\title{
Social and Environmental Predictors of Maternal Depression in Current and Recent Welfare Recipients
}

\author{
Kristine Siefert, Ph.D., M.P.H., Phillip J. Bowman, M.D., M.P.H., Colleen M. Heflin, M.P.P.,
} Sheldon Danziger, Ph.D., David R. Williams, Ph.D., M.P.H.

Depression is highly prevalent in welfare recipients, and is associated with failure to move from welfare to work. This paper examines the relationship between social and environmental factors in a large, community-based sample of mothers who currently or recently received welfare benefits. Specific and modifiable risk factors related to poverty, gender, and race were found to predict major depression beyond traditional risk factors. Research and practice implications are discussed.

$\mathrm{T}$ The National Comorbidity Study (NCS) lifetime prevalence estimate for $D S M-I I I-R$ major depressive disorder in women is $18.6 \%$, and the 12-month prevalence is $11.0 \%$ (Kessler et al., 1996). Although the NCS contains no information on welfare recipients, recent research has documented that they have considerably higher rates of depression. In a case-control study of homeless and housed women receiving welfare, Salomon, Bassuk, and Brooks (1996) found a lifetime prevalence rate of major depression of $42.9 \%$, and in a one-year follow-up of barriers to work among mothers receiving welfare following passage of the Personal Responsibility and Work Opportunity Reconciliation Act of 1996, Danziger et al. (2000) found the 12-month prevalence of major depression to be $25 \%$. An important finding of the latter study was that mothers who met the diagnostic screening criteria for major depression were significantly less likely to have made the transition from welfare to work than mothers who did not meet the criteria.

The public health burden imposed by maternal major depression includes not only significant impairment in social and occupational functioning and increased health care costs, but its profoundly adverse impact on children's social, behavioral, and emotional functioning, as well as on offspring diagnostic outcomes in adolescence and early adulthood (Field, 1992; Leadbeater \& Bishop, 1994; Weissman, Warner, Wickramaratne, Moreau, \& Olfson, 1997). Although psychiatric epidemiology has identified biological, social, and demographic risk factors for depression, the mechanisms whereby these risk factors lead to depression are unclear, and many of the major risk factors that have been identified, such as low socioeconomic status (SES), female sex, and genetic endowment, are global, not readily modified, or otherwise provide little direction for preventive intervention (Culbertson, 1997; National Advisory Mental Health Council Workgroup on Mental Disorders Prevention Research, 1998; Weissman \& Olfson, 1995).

Moreover, despite its high prevalence and substantial morbidity and cost, depression frequently remains undetected or inadequately treated, even though specific and successful interventions are available (Ford, 1994; Gerber et al., 1989; Kessler et al., 1994; Perez-Stable, Miranda, Munoz, \& Ying, 1990; Ustun \& Von Korff, 1995; Von Korff, Ormel,

A revised version of a paper submitted to the Journal in October 1999. Research was supported in part by NIMH grant R-24MH51363 and grants from the Charles Stewart Mott and Joyce Foundations. Authors are at: NIMH Research Center on Poverty, Risk, and Mental Health, School of Social Work, University of Michigan, Ann Arbor (Siefert, Heflin, Danziger); University of California Medical Center, Los Angeles (Bowman); and Institute for Social Research, Ann Arbor (Williams). 
Katon, \& Lin, 1992; Von Korffet al., 1987; Wells et al., 1989; Wells, Sturm, Sherbourne, \& Meredith, 1996). This is of great concern, as the course of major depression becomes recurrent in $50 \%-70 \%$ of new cases, the risk of recurrence rises dramatically with successive episodes, and the severity of subsequent episodes tends to increase (Coryell, Endicott, \& Keller, 1990; Kupfer, 1993).

In the present research on a sample of welfare mothers, it was hypothesized that specific and potentially modifiable social and environmental risk factors related to gender, race, and poverty would predict major depressive disorder beyond traditional and more general risk factors, and that the effects of these risk factors would be cumulative. In addition, it was hypothesized that protective factors would reduce the effects of specific social and environmental risks. Welfare recipients are, by definition, poor, and they are disproportionately women of color. The conceptual framework for this study derives from epidemiological theories of the social production of disease, which posit that the relative social and economic positioning of people determines their exposure to risk factors, including health-related behavior-and that what is measured on the population level, i.e. the distribution of disease, reflects this positioning (Kreiger, Rowley, Herman, Avery, \& Phillips, 1993; Kreiger \& Zierler, 1995; Link \& Phelan, 1995; MacIntyre, Maclver, \& Sooman, 1993; McKinlay, 1993; Vander Stoep \& Link, 1998; Williams, 1997; Williams, Yu, Jackson, \& Anderson, 1997).

This work also draws on theoretical and empirical studies of risk and protective factors for mental disorders, which indicate that exposure to multiple risk factors can have cumulative effects, that risk factors can modify and potentiate one another, and that the effects of exposure to risk factors can be mitigated by individual and social characteristics that serve protective functions (Coie et al., 1993; Reiss \& Price, 1996; Boyce et al., 1998).

\section{Poverty, Gender, Race, and Depression}

Both gender and low SES are strongly associated with increased risk of depression, but the pathways through which they influence mood disorders are not well understood. Epidemiologic studies worldwide have established that depression is twice as prevalent in women as in men, and there is a peak in first onsets of depression in the childbearing and child-rearing years (Culbertson, 1997; Kessler et al., 1994; Weissman \& Olfson,
1995). Mothers of young children are at particular risk; studies of maternal depression in pediatric primary care settings have found rates ranging from $12 \%$ to $47 \%$ (Heneghan, Silver, Bauman, Westbrook, \& Stein, 1998). Mothers with several young children, single mothers, and mothers in poverty are at even higher risk of depression ( $\mathrm{Hob}$ foll, Ritter, Lavin, Hulsizer, \& Cameron, 1995; Heneghan et al., 1998). Estrogen cyclicity may enhance vulnerability to the effects of exposure to stressors, and hence to depression (Seeman, 1997).

Psychological theories have posited that personality differences between women and men explain the higher prevalence of depression in women (Culbertson, 1997; Padgett, 1997; Seeman, 1997). One such theory proposes that women receive "helplessness training," with consequent deficits in coping and explanatory styles accounting for their excess depression. Another proposes that women internalize blame for their incompetence or failure, while men tend to externalize their shortcomings, leading to anger. However, empirical support for these classic theories of depression is sparse (Seeman, 1997). More recently, Nolen-Hoeksema (1990) has proposed that women have a more passive, ruminative coping style in dealing with problems, compared with a more active, distraction-oriented style in men, which accounts for some of the gender differences in depression (Culbertson, 1997; Nolen-Hoeksema, 1994; Seeman, 1997). There is compelling research evidence for the relationship between rumination and depressed mood, but it is not clear why women ruminate more than men. A recent study by Almeida and Kessler (1998) found that gender differences in psychological distress were largely due to women experiencing more daily stressors and hence more onsets of distress than men. Other research suggests that the effects of social environmental stress in the development of major depression may interact with psychological factors such as personality style, cognitive schemata, and self-esteem (Breslau \& Davis, 1986; Kendler, Kessler, Neale, Heath, \& Eaves, 1993; Roy, 1987).

Women are overrepresented among the poor, and poverty is clearly implicated as an etiological factor in depression. Higher rates of depression have consistently been found among both black women and white women of lower SES (Blazer, Kessler, McGonagle, \& Swartz, 1994; Williams, Takeuchi, \& Adair, 1992). Bruce, Takeuchi, and Leaf (1991) reported an odds ratio for depression 
of 2.29 for the poor versus the non-poor, after adjusting for gender. Poverty increases the likelihood of exposure to the acute and chronic stressors associated with depression (e.g., personal experiences of violence, residing in a violent neighborhood, unemployment and low-wage work, limited opportunities, and poor health) and with decreased access to the material and emotional resources that could buffer the impact of stressful life events and conditions (e.g., money for goods and services, the presence of a supportive partner) (Bassuk, Browne \& Buckner, 1996; Hobfoll et al., 1995; Padgett, 1997; Salomon et al., 1996).

Women of color, who are overrepresented among low-income mothers, are exposed to the additional risk of racial discrimination. Recent research suggests that the subjective experience of discrimination may be an important risk factor for mental health problems. Studies of diverse racial and ethnic groups have found that perceptions of discrimination are adversely related to mental health (Amaro, Russo, \& Johnson, 1987; Noh, Beiser, Kaspar, Hou, \& Rummens, 1999; Landrine \& Klonoff. 1996; Rumbaut, 1994; Thompson, 1996; Williams, in press; Williams \& Chung, in press). Several studies have documented that, although African-Americans have rates of mental illness comparable to or lower than those of whites (Kessler et al., 1994; Robins \& Regier, 1991), blacks report more experiences of racial discrimination, which is positively associated with psychological distress, depressive symptoms, and major depression (Kessler, Mickelson, \& Williams, 1999; Ren, Amick, \& Williams, 1999; Williams et al., 1997).

Clinical studies have found that the principal physical change in approximately half of patients with major depression is overactivity of the hypothalamic-pituitary-adrenocortical (HPA) axis and impaired negative feedback inhibition resulting in increased circulating cortisol concentrations (Kathol, Jaeckle, Lopez, \& Meller, 1989; Kiraly, Ancill, \& Dimitrova, 1997; Stokes, 1995). Hypercortisolemia alters mood, cognition, and behavior, and prolonged elevations in cortisol seem to have neurotoxic effects (Checkley, 1996; Rubin, 1989). The HPA axis is highly responsive to stress, and some studies exploring the effects of life events and chronic difficulties have shown sustained circulating levels of cortisol (Checkley, 1992). Both past life events and major depressive episodes may alter HPA system responsiveness to subsequent environmental stress in a manner that can increase the risk for future
HPA dysregulation and major depression (Checkley, 1992; Stokes, 1995). Regardless of their respective pathways, the biological and psychological factors that interact with social environmental stress contribute to dysregulation of central nervous system networks with significant perturbations of neurotransmitter and neuroendocrine systems (Checkley, 1992, 1996; Heuser, 1998; Post, 1992). Thus, although there is strong evidence for biologic contributors to maternal depression, social and environmental factors are important. Some recent research suggests that the influence of environmental stress is greater than that of biologic predisposition (Kendler, Karkowski, \& Prescott, 1998; Kendler et al., 1993, 1995; Kessler et al., 1994).

\section{Identifying Depression in Low-Income Mothers}

Although early identification and treatment of depression is a major public health goal, for lowincome mothers, among whom the rate of depressive symptoms is high and sociodemographic risk factors for depression are almost universal, traditional risk factors do not necessarily identify those who are depressed. A recent study of relatively homogeneous inner-city mothers of young children found that traditional sociodemographic characteristics identified as risk factors for depressive symptoms were not useful in detecting those with high levels of such symptoms; however, maternal self-ratings of health, physical functioning, and financial status did predict maternal depressive symptoms (Heneghan et al., 1998). It should be noted, though, that these investigators measured depressive symptoms, and it is not known whether the findings can be generalized to the prediction of major depression.

Building on and extending previous research, the present study examines specific social and environmental predictors of major depression in a large, community-based sample of current and former welfare recipients. The identification of specific and modifiable factors associated with major depression in this population has important implications for detection, intervention, and public policy, as well as for advancing knowledge about the etiology of major depression, its prevention, and mental health promotion.

\section{METHOD}

\section{Study Design and Sample}

The data presented here are from the Women's Employment Study. This cross-sectional survey 
was designed to identify barriers to employment among 753 mothers with children who were receiving cash welfare in an urban Michigan county in February 1997. The study assessed a broad array of factors that could conceivably affect recipients' transition to employment, including 12 month mental health diagnoses (Danziger et al., 2000). It thus provides a unique opportunity for examining social and environmental predictors of major depression in this population.

Face-to-face, in-home, structured interviews lasting about one hour were conducted by trained staff of the Survey Research Center of the Institute for Social Research, University of Michigan, between August and December 1997. To be eligible, women had to reside in the study county, be receiving cash assistance in February 1997, be a U.S. citizen aged 18-54, and have a racial identity of white or African-American (there were not enough Hispanics or other minority residents of this county to conduct reliable analyses).

A simple random sampling scheme was used, with cases systematically selected with equal probability from an ordered list of eligible single mothers. To derive a representative sample of the metropolitan area and the study population, cases were proportionately selected by zip code, race (African American or non-Hispanic white), and age. The study enjoyed an exceptionally high response rate of $86.2 \%$ ( 753 completed interviews out of 874 sample cases). Excluded nonsample cases $(N=26)$ consisted of instances in which an individual resided outside the study county, was institutionalized for the duration of the data collection period, or had an address at which no housing unit existed.

The study's high response rate is attributable to several factors. First, the research team worked closely with the interviewers and survey manager during the period of survey development and pretesting. Staff from the research team consulted almost weekly with the survey manager and interviewers during the course of the study, so that problems, once identified, could be resolved. Secondly, the women employed as interviewers were highly experienced in survey research and resided in or near the study county. Thirdly, substantial effort was devoted to tracking respondents. The median number of contacts per completed interview was three (range 1-28). Interviewers had the authority to continue to pursue a respondent as long as they thought it was feasible. Fourthly, interviews were scheduled in the homes of the respon- dents at a time of their choosing, including nights and weekends. Finally, respondents were paid $\$ 30$ for participating in the study.

\section{Variables and Definitions}

The dependent variable for the analysis was major depressive disorder. The measurement of this disorder was based on the definitions and criteria specified in the DSM-III-R (American Psychiatric Association, 1987). The psychiatric diagnosis was operationalized in screening versions of the World Health Organization's (WHO) Composite International Diagnostic Interview, Version 1.0 (CIDI) (WHO, 1990; Kessler et al., 1999), a structured interview schedule designed to be used by trained interviewers who are nonclinicians to assess the prevalence of specific psychiatric disorders (Robins et al., 1988). WHO field trials and other methodological studies (Blazer et al., 1994; Wittchen. 1994) have documented acceptable test-retest reliability and clinical validity of CIDI diagnoses.

The independent variables examined included those sociodemographic and other personal characteristics known to be associated with increased risk of depression, including a childhood history of abuse, limitations in physical activities due to health problems, having a child with a chronic health problem, and economic status (Blazer et al., 1994; Levitan et al., 1998; Olfson et al., 1997; Silver, Westbrook, \& Stein, 1998; Young, Abelson, Curtis, \& Nesse, 1997). Exposure to seven social and environmental risk factors was also examined: l) residence in a high poverty census tract; 2) residence in a hazardous neighborhood; 3) food insufficiency; 4) poverty-related stressful life circumstances; 5) exposure to severe domestic violence; and perceptions of ever having experienced discrimination at work or when seeking employment based on 6) race or 7) gender. Because generalized anxiety disorder and posttraumatic stress disorder (PTSD) are also highly prevalent among poor women, and both are highly comorbid with major depression, the research controlled for these disorders, as well as for drug and alcohol dependence, both of which are known to be associated with depression. Finally, factors thought to confer protection against depression - sense of mastery, high degree of perceived social support, presence of a spouse or partner in respondent's household at time of interview - were included.

Health-related physical limitations. These were assessed using questions from the SF-36 Physical 
Functioning subscale (Ware \& Sherbourne, 1992). Respondents who scored in the lowest age-specific quartile (based on general population norms) were defined as having physical limitations.

Childhood abuse. This was defined by a positive response to a Life Events subscale question used in the NCS: "Were you ever physically abused as a child?" (Kessler et al., 1994).

Child physical or mental health problems. These were established by a positive response to the question: "Do any of your children have a physical, learning, or mental health condition that limits their regular activities?"

Economic status. This was measured using the official ratio of total family income, including the estimated value of the Earned Income Tax Credit, to the federal poverty line for a given family size (Danziger \& Gottschalk, 1995; U.S. Bureau of the Census, 1998). Any woman whose monthly income was above one-twelfth of the annual poverty line (i.e., not officially poor) was categorized as not poor.

Residence in a high poverty area or hazardous neighborhood. The former was defined as living in a census tract with a poverty level of $40 \%$ or higher (Jargowsky, 1997), the latter as a mean score greater than two on a scale developed by Furstenberg, Cook, Eccles, Elder, and Sameroff (1998), which asks respondents to rate the presence of such problems as muggings, gangs, vandalism, and lack of police protection in their neighborhood. Responses are coded from one ("not at all") to three ("very much").

Food insufficiency. Defined by a response of "sometimes" or "often" to a question from the third National Health and Nutrition Examination Survey: "Which of the following best describes the amount of food your household has to eatenough to eat, sometimes not enough to eat, or often not enough to eat?" (National Center for Health Statistics, 1994).

Stressful life circumstances. Defined as four or more positive responses to ten questions adapted from the Difficult Life Circumstances scale (Booth, Mitchell, Barnard, \& Spieker, 1989), as adapted for use in a study of young mothers in poverty (Quint, Bos, \& Polit, 1997). This scale measures ongoing or habitual stress that is often a feature of living in poor communities, e.g., "Have you had trouble finding a place to live?" Additional measures of material deprivation were included for the present study, e.g., "Have you been homeless in the last 12 months?"; "Has your gas or electricity been turned off in the last 12 months because you couldn't afford to pay the bill?"

Domestic violence. This was assessed via items from the Conflict Tactics Scale (Straus \& Gelles, 1986), a widely used measure of family violence. Respondents were defined as having experienced domestic violence if they reported any incidents of severe violence (e.g., hit with a fist or object, beaten, or choked) with in the past year.

Discrimination based on race or gender. Items assessing perceived discrimination were adapted from surveys by Bobo (1995) and Williams et al. (1997), and consisted of a series of questions asking about unfair treatment while seeking employment or in the workplace, e.g., for racial discrimination: "Did your supervisor or boss ever use racial slurs?"; for gender discrimination: "Were you ever sexually harrassed?"

Control variables. The variables of generalized anxiety disorder, PTSD, alcohol dependence, and drug dependence were assessed using the relevant CIDI diagnostic screening criteria (Kessler, Andrews, Morczek, Ustun, \& Wittchen, in press; Robins et al., 1988; Wittchen, 1994; WHO, 1990). The hypothesized protective factor "sense of mastery" was assessed using the seven-item Mastery Scale (Pearlin, Menaghan, Lieberman, \& Mulan, 1981), designed to measure perceived mastery over one's life or self-efficacy. Respondents who scored in the highest quartile were defined as having high mastery. Social support, also a hypothesized protective factor, was measured by means of a fiveitem summary scale; respondents were asked if there is someone they can count on to run errands, lend money, provide encouragement, watch their children, and lend a car or give a ride if needed. Those answering positively to at least four of the items were defined as having high social support.

\section{Data Analysis}

Four nested logistic regression models were used to examine the independent effects of five sets of factors on the probability of caseness (i.e., meeting the diagnostic screening criteria) for major depressive disorder.

Model 1 estimated the probability of exhibiting caseness for depression as a function of the mothers' fixed and background demographic and personal characteristics. Race was a dummy variable coded 1 for African American. In anticipation of nonlinearities in the effect of age on depression, 
three categorical variables were utilized: ages $18-24$ as the omitted reference group, ages $25-34$, and ages $\geq 35$. Educational level was entered as a dummy variable coded 1 for those with less than a high school diploma or GED, and physical limitations as a dummy variable coded 1 as described above. The model controlled for childhood abuse for those who reported having been physically abused as a child, and added the household's monthly economic status, a dummy variable coded 1 for the non-poor.

Model 2 added a composite social and environmental risk index, which includes the seven separate risk factors enumerated above. The absence or presence of each risk factor is coded 0 or 1 . Model 3 controlled for generalized anxiety disorder, PTSD, drug dependence, and alcohol dependence.

Finally, in Model 4, the three hypothesized protective factors were entered: sense of mastery, social support, and presence of a spouse or partner. Using SPSS Version 8.01 software, odds ratios and $95 \%$ confidence intervals for unit changes in each factor were computed; $10 \%$ significance levels are also reported in order to identify potentially important trends that may not have reached statistical significance in the logistic regression analysis due to sample size.

\section{RESULTS}

Sample Characteristics and Maternal Depression

TABLE 1 summarizes the mothers' sociodemographic characteristics and the distribution of hypothesized risk and protective factors and control variables by maternal depression status. Of the 753 observations, 705 had no missing data on any of the included variables; these comprise the analysis sample. Of the mothers, $56 \%$ were African American and $44 \%$ non-Hispanic white. About $30 \%$ lacked a high school degree, one-third were high school graduates, and one-third had more than a high school education. Median age was 28 , with $75 \%$ below the age of 35 . Fifty-eight percent were working 20 hours or more weekly at the time of the survey, and $28 \%$ were no longer receiving welfare; $47 \%$ had monthly income exceeding the poverty line.

More than one-quarter of the mothers met the CIDI diagnostic screening criteria for major depressive disorder. Approximately one-third lived in a high-poverty census tract, $16 \%$ perceived their neighborhood as a hazardous place to live, and almost $28 \%$ described multiple stressful life circum-
Table 1

MOTHERS' BACKGROUND CHARACTERISTICS AND RISK, PROTECTIVE, AND CONTROL FACTORS BY DEPRESSION STATUS $(N=705)$

\begin{tabular}{|c|c|c|c|c|}
\hline \multirow{3}{*}{$\begin{array}{l}\text { VARIABLE } \\
\text { Demographics }\end{array}$} & \multicolumn{4}{|c|}{ PREVALENCE IN: } \\
\hline & \multicolumn{2}{|c|}{$\begin{array}{l}\text { SAMPLE } \\
\&(S D)\end{array}$} & \multirow[t]{2}{*}{$\begin{array}{c}\text { DE- } \\
\text { PRESSED }\end{array}$} & \multirow[t]{2}{*}{$\begin{array}{l}\text { NOT DE- } \\
\text { PRESSED }\end{array}$} \\
\hline & & & & \\
\hline African-American & 55.5 & $(0.50)$ & 48.6 & $57.8^{* *}$ \\
\hline Age $25-34$ & 46.2 & $(0.50)$ & 45.9 & 46.4 \\
\hline Age $\geq 35$ & 25.4 & $(0.44)$ & 30.4 & $23.7^{*}$ \\
\hline$<$ High school education & 29.9 & $(0.46)$ & 33.7 & 28.6 \\
\hline Childhood abuse & 17.0 & $(0.38)$ & 32.0 & $11.8^{* *}$ \\
\hline Mother physical limits & 44.5 & $(0.50)$ & 61.3 & $38.7 * *$ \\
\hline Child w/health problem & 21.0 & $(0.41)$ & 32.6 & $17.6^{* *}$ \\
\hline Economic status (not poor) & 47.0 & $(0.50)$ & 42.5 & 48.5 \\
\hline \multicolumn{5}{|l|}{$\begin{array}{l}\text { Social \& Environ- } \\
\text { mental Risk Factors }\end{array}$} \\
\hline High poverty census tract & 33.8 & $(0.47)$ & 32.6 & 34.2 \\
\hline Hazardous neighborhood & 16.0 & $(0.37)$ & 21.0 & $14.3^{\text {***}}$ \\
\hline Food insufficiency & 24.5 & $(0.43)$ & 40.3 & $19.1^{* *}$ \\
\hline Stressful life situation & 27.5 & $(0.45)$ & 47.0 & $20.8^{* *}$ \\
\hline Domestic violence & 15.0 & $(0.36)$ & 25.4 & $11.5^{* *}$ \\
\hline Race discrimination & 29.7 & $(0.46)$ & 38.1 & $26.7^{* *}$ \\
\hline Sex discrimination & 34.6 & $(0.48)$ & 44.8 & $31.1^{=*}$ \\
\hline \multicolumn{5}{|l|}{ Psychiatric Comorbidity } \\
\hline Generalized anxiety & 7.1 & $(0.26)$ & 18.2 & $3.2^{* *}$ \\
\hline PTSD (12 month) & 14.9 & $(0.36)$ & 30.9 & $9.4^{* *}$ \\
\hline Drug dependence & 3.3 & $(0.18)$ & 8.3 & $1.5^{* *}$ \\
\hline Alcohol dependence & 2.8 & $(0.17)$ & 6.6 & $1.5^{* *}$ \\
\hline \multicolumn{5}{|l|}{ Protective Factors } \\
\hline High mastery score & 28.8 & $(0.45)$ & 16.6 & 33.0** \\
\hline High social support & 80.4 & $(0.40)$ & 69.6 & $84.2^{* *}$ \\
\hline Married or cohabiting & 24.0 & $(0.43)$ & 21.5 & 24.8 \\
\hline
\end{tabular}

"Difference between depressed/not depressed signif. at .10 level. "Difference between depressed/not depressed signif. at 05 level.

stances. Almost a quarter of the mothers reported sometimes or often not having enough to eat in their household over the past year; $15 \%$ reported having experienced domestic violence during the same period; and about one-third reported that they had experienced discrimination because of their race or gender.

As expected, depressed mothers were significantly more likely than nondepressed mothers to report having been abused as a child $(32.0 \%$ vs. $11.8 \%$ ), having physical limitations $(61.3 \%$ vs. $38.7 \%$ ), and having a child with a chronic health problem ( $32.6 \%$ vs. $17.6 \%)$. With the exception of residence in a high-poverty census tract, all the other hypothesized social and environmental risk factors were significantly more prevalent among the depressed mothers. As expected, comorbid generalized anxiety disorder, PTSD, and drug and alcohol dependence were much more prevalent among depressed mothers. Of the three protective factors, maternal sense of mastery and having a high level of social support were significantly more prevalent among the nondepressed mothers, but the presence of a spouse or partner was not. 
Table 2

SOCIAL AND ENVIRONMENTAL RISK INDEX BY MATERNAL DEPRESSION STATUS

\begin{tabular}{lrrrr}
\hline \hline & \multicolumn{4}{c}{ PREVALENCE IN: } \\
\cline { 2 - 5 } $\begin{array}{l}\text { VARLABLE } \\
\text { No. of Risk Factors }\end{array}$ & SAMPLE & $($ SD $)$ & DE- & $\begin{array}{c}\text { NOT DE- } \\
\text { PRESSED PRESSED }\end{array}$ \\
0 & 20.4 & $(0.40)$ & 9.4 & $24.2^{*}$ \\
1 & 26.8 & $(0.44)$ & 20.4 & $29.0^{*}$ \\
2 & 24.3 & $(0.43)$ & 22.1 & 25.0 \\
3 & 15.0 & $(0.36)$ & 23.2 & $12.2^{*}$ \\
4 & 8.1 & $(0.27)$ & 11.6 & $6.9^{*}$ \\
$5+$ & 5.4 & $(0.23)$ & 13.3 & $2.7^{*}$ \\
\hline
\end{tabular}

"Difference between depressed/not depressed signif. at .05 level.

Cumulative Risk Factors and Maternal Depression

TABLE 2 presents the cumulative distribution of the seven social and environmental risk factors among the mothers by depression status. As hypothesized, there is a significant association between cumulative risk factors and maternal depression. For example, women with three or more risk factors account for $28.5 \%$ of the sample, but $48.1 \%$ of the women who are depressed.

TABLE 3 presents results from the nested logistic regression analysis. In Model 1, maternal sociodemographic and personal characteristics are entered. Having been physically abused as a child, having limitations in physical functioning, or hav- ing a child with an activity-limiting chronic health problem significantly increased the likelihood of major depression ( $\mathrm{OR}=3.48,2.45$, and 2.05 , respectively). African Americans and the non-poor are less likely to have major depression, but the coefficients are not significant.

Model 2 adds the cumulative risk factor index. As hypothesized, having more than a single risk factor significantly increases the odds of maternal depression, and the increase in depression is nonmonotonic. For example, the odds ratios for two, three and four risk factors range from 2.13 to 4.44 , and then jump to 10.91 for those with five or more risk factors. While this nonlinearity may be an artifact of sample size, it is consistent with theory proposing that individual risk factors can modify and potentiate one another (Coie et al., 1993; Reiss \& Price, 1996); other cumulative risk factor research has reported similar patterns (Sameroff, Seifer, Baldwin, \& Baldwin, 1993; Sameroff, Seifer, $\&$ Bartko, 1997). Adding the cumulative risk factor index reduces the size of the effect of childhood abuse on maternal depression status, suggesting an association between the effects of having been abused as a child and subsequent exposure to potentially depressive social and environmental risk factors.

Table 3

ODDS RATIOS (OR) AND 95\% CONFIDENCE INTERVALS FOR PREDICTORS OF MATERNAL DEPRESSION (N=705)

VARIABLE
Demographics
African American
Age $25-34$
Age 35 and older
Experienced childhood abuse
Less than high school education
Mother's physical limitations
Child with health problem
Economic status (not poor)
Social/Environmental Risk Index
Presence of 1 risk factor
Presence of 2 risk factors
Presence of 3 risk factors
Presence of 4 risk factors
Presence of $5+$ risk factors
Psychiatric Comorbidity
Generalized anxiety disorder
PTSD (12 month)
Drug dependence
Alcohol dependence
Protective Factors
High mastery score
High social support
Lives with husband or partner
Cox \& Snell $R^{2}$
-2 Log likelihood

\begin{tabular}{lc}
\multicolumn{2}{c}{ MODEL 1} \\
\hline OR & $95 \% \mathrm{Cl}$ \\
& \\
0.75 & $0.52-1.09$ \\
1.28 & $0.82-2.01$ \\
1.29 & $0.78-2.13$ \\
$\mathbf{3 . 4 8 * *}$ & $2.26-5.37$ \\
1.09 & $0.73-1.62$ \\
$\mathbf{2 . 4 5 * *}$ & $1.70-3.54$ \\
$\mathbf{2 . 0 5 * *}$ & $1.36-3.10$ \\
0.77 & $0.53-1.12$
\end{tabular}

$\frac{\text { MODEL } 2}{\text { OR } 95 \% \mathrm{CI}}$

$0.62 * \quad 0.42-0.92$

$1.32 \quad 0.83-2.12$

$1.37 \quad 0.81-2.30$

$2.88^{* *} \quad 1.83-4.52$

$0.96 \quad 0.63-1.47$

$2.33^{* *} 1.59-3.41$

$1.85^{* *} 1.20-2.84$

$0.72 \quad 0.49-1.07$

$1.76^{\dagger} \quad 0.92-3.37$

$2.13^{*} \quad 1.12-4.08$

4.44** 2.26-8.74

$3.59^{* *} 1.65-7.80$

$10.91 * * 4.47-26.65$

2 Log likelihood
0.109

721.811

\begin{tabular}{ll}
\multicolumn{2}{c}{ MODEL 3 } \\
\hline OR & $95 \% \mathrm{CI}$ \\
& \\
$0.61 *$ & $0.41-0.90$ \\
1.13 & $0.69-1.84$ \\
1.22 & $0.71-2.09$ \\
$2.30^{* *}$ & $1.44-3.70$ \\
0.92 & $0.59-1.42$ \\
$2.16^{* *}$ & $1.46-3.21$ \\
$2.09^{* *}$ & $1.34-3.26$ \\
0.74 & $0.49-1.11$ \\
& \\
1.57 & $0.81-3.06$ \\
$1.77^{\dagger}$ & $0.90-3.45$ \\
$3.69 * *$ & $1.84-7.42$ \\
$2.41 *$ & $1.06-5.47$ \\
$5.01 * *$ & $1.91-13.10$ \\
& \\
$3.74 * *$ & $1.86-7.52$ \\
$2.37^{* *}$ & $1.43-3.92$ \\
2.40 & $0.82-7.03$ \\
1.97 & $0.66-5.83$
\end{tabular}

0.201

644.937

\begin{tabular}{lc}
\multicolumn{2}{c}{ MODEL 4 } \\
\hline OR & $95 \%$ Cl \\
& \\
$0.58^{*}$ & $0.38-0.89$ \\
1.06 & $0.64-1.73$ \\
1.08 & $0.62-1.88$ \\
$2.25 * *$ & $1.39-3.64$ \\
0.83 & $0.53-1.30$ \\
$2.03^{* *}$ & $1.36-3.02$ \\
$2.10^{* *}$ & $1.34-3.28$ \\
0.78 & $0.52-1.18$ \\
& \\
1.54 & $0.78-3.02$ \\
1.64 & $0.83-3.23$ \\
$3.67^{* *}$ & $1.81-7.43$ \\
$2.088^{*}$ & $0.90-4.80$ \\
$4.37^{* *}$ & $1.65-11.60$ \\
& \\
$3.46^{* *}$ & $1.72-6.97$ \\
$2.35^{* *}$ & $1.41-3.92$ \\
2.21 & $0.77-6.38$ \\
1.91 & $0.64-5.70$ \\
& \\
$0.54 *$ & $0.33-0.89$ \\
$0.62 *$ & $0.39-0.98$ \\
0.79 & $0.48-1.30$ \\
& 0.215 \\
632.729 \\
\end{tabular}

679.801
0.215
632.729 
Model 3 controls for comorbid psychiatric disorders. Meeting the diagnostic criteria for generalized anxiety disorder and PTSD more than doubles the odds of maternal depression; the coefficients on drug and alcohol dependence are large and positive, but not significant. Furthermore, adding these variables reduces the effect sizes of childhood abuse and subsequent exposure to social and environmental risk factors.

In Model 4, the protective factors are entered and, as predicted, having high social support and high mastery decreases the odds of depression by about half. The sizes of the coefficients on the risk factors decrease, but most remain significant. Model 4 has more explanatory power than Model 1. The log likelihood decreases and the Cox and Snell $R^{2}$ almost doubles from .109 to .215 .

\section{DISCUSSION}

This study of major depression in current and recent welfare recipients supports and extends Heneghan et al.'s (1998) findings that, in a nonclinical sample of high-risk mothers, many traditional risk factors do not identify maternal depressive symptoms. Moreover, as hypothesized, the present study found that specific and potentially modifiable stressors related to recipients' gender, race, and impoverished circumstances remained significant and substantial predictors of maternal depression, after controlling for sociodemographic characteristics and other traditional risk factors. The likelihood of meeting the DSM-III-R diagnostic screening criteria for recent major depressive disorder increased with the number of social and environmental risk factors present, and decreased among mothers who reported higher levels of social support and among those who perceived themselves as having greater control over their lives. Although the cross-sectional nature of these data precludes causal inference, the findings are consistent with epidemiologic theories of the social production of disease, and add to the growing body of research supporting the depressive effects of social and environmental stressors.

In a study documenting high rates of victimization among homeless and poor housed women on welfare, Salomon et al. (1996) noted that the real experiences of poor women's lives are absent from public discourse. The present findings support the need for programs and policies that reduce environmental risk factors for major depression among welfare mothers. They also have implications for future research on the etiology of major depression and its comorbidities, for its detection in nonclinical settings, and for the development of preventive interventions (NIMH/NIH, 1996; NAMHC, 1998).

\section{Implications for Research}

The findings of this study are consistent with data from large epidemiological studies that indicate psychiatric comorbidity is substantial for major depressive disorder (Kessler et al., 1996; Robins \& Regier, 1991; Wittchen, Essau, von Zewrssen, Krieg, \& Zaudig, 1992). Generalized anxiety disorder was significantly more prevalent among those mothers who met the diagnostic criteria for major depression, a finding consistent with those of the NCS and other epidemiological studies (Kessler et al., 1994). Although there has been considerable debate regarding the reasons for this overlap, epidemiological studies suggest that the two disorders may share a common genetically influenced neurobiologic vulnerability, and that environmental factors increase the risk for both disorders (Judd et al., 1998; Kendler, 1997; Kendler et al., 1995; Merikangas, 1990).

The mothers in this sample also showed a high degree of comorbidity for the 12-month diagnoses of PTSD and major depression. As with generalized anxiety disorder, the causes of this co-occurrence are largely unsettled. Although trauma exposure is the key determinant of PTSD, there are substantial data associating a prior traumatic experience with the diagnosis of major depressive disorder (Bleich, Koslowsky, Dolev, \& Lerer, 1997; Breslau, Davis, Peterson, \& Schultz, 1997; Kessler, Davis \& Kendler, 1997; Shalev et al., 1998). However, the neurobiologic response patterns of major depressive disorder and PTSD appear to differ (Yehuda, 1998). Although comorbidity may be related to overlapping diagnostic criteria for the disorders, studies show that most individuals would still reach the diagnostic threshold without the overlapping symptoms (Blanchard, 1998; Bleich et al., 1997; Solomon et al., 199l). Furthermore, while the two disorders may have a shared predisposition, studies of their chronological relationship indicate that neither is consistently primary in relation to the other (Breslau et al., 1997; Shalev et al,, 1998). Several studies have suggested that depression may represent a vulnerability factor that makes PTSD more likely after trauma exposure (Breslau et al., 1997; Bromet, Sonnega, \& Kessler, 1998). Both treatment and 
longitudinal population-based studies reveal that comorbid major depression is associated with more severe symptoms, poorer overall functioning, a more protracted course of illness, less positive treatment outcomes, and increased risk of suicide (Brown, Schulberg, Madonia, Shear, \& Houck, 1996, Judd et al., 1998; Kendler et al., 1995; Sherbourne \& Wells, 1997). A better understanding of the pathways through which environmental risk factors operate in the etiology of comorbid major depression in high-risk mothers is an important goal for future research, with substantial clinical and public health impact.

Most studies of the role of environmental risk factors in major depression have focused on the assessment of various combinations of "personal events" (i.e., things that happen primarily to the respondent, such as assault, divorce, job loss, serious illness, or major financial problem) and "network events" (i.e., things that happen to or in interaction with someone from the respondent's immediate social network, such as death of a spouse or serious interpersonal conflict with a relative, neighbor, or close friend) (Kendler et al., 1995, 1998; Kendler \& Karkowski-Shuman, 1997) The findings of recent genetic-epidemiologic studies on the role of such events in the etiology of mental disorders have been cited to support the hypothesis of "genetic control" of exposure to the environment. According to this hypothesis, genetic factors influence the probability that individuals will select themselves into high- versus low-risk environments, in contrast with the "genetic sensitivity" hypothesis, which holds that genes render individuals relatively vulnerable or invulnerable to the pathogenic effects of environmental stress (Kendler, 1998)

In keeping with the current study's focus on social factors in the production of disease, risk factors were examined beyond those that are primarily personal in nature, to include those that arise from the individual's relative social and economic positioning, e.g., experiences of gender and race discrimination, living in a hazardous neighborhood, poverty status (Kreiger et al., 1993; Williams, 1997). Specific and modifiable social and environmental risk factors that have not been examined in previous research on depression, or that have not been examined in combination with one another, were found to be significant and $\mathrm{cu}-$ mulative predictors of major depression among current and recent welfare recipients.
While causality cannot be inferred from the present cross-sectional data, the findings do suggest the need for a broader conceptualization and more detailed examination of the role of the social environment in the etiology of mental disorders. Unlike genetic endowment, many social and environmental risk factors are relatively amenable to elimination or modification. And clarification of the role of such factors in the etiology of major depression could aid in the development of preventive interventions, as well as reduce the likelihood of comorbidity, disability, and relapse.

\section{Implications for Intervention}

The high rate of major depression in this sample of current and recent welfare recipients raises important issues regarding unmet need for mental health services. Although one-quarter of the sample met the CIDI diagnostic screening criteria for major depressive disorder in the past year, only $13 \%$ reported ever having received treatment for a mental health problem. As noted above, maternal depression is often unrecognized and untreated, even in health care settings. This is of particular concern for welfare recipients. Despite the decoupling of Medicaid from cash welfare, Medicaid enrollment of the welfare population has declined (Chavkin, Romero, \& Wise, 2000), and a recent survey found that almost half of former recipients are uninsured a year or more after leaving welfare (Garrett \& Holahan, 2000). Moreover, many lowincome mothers have no regular source of care (Bindman, Grumbach, Osmond, Vranizan, \& Stewart, 1996; Cornelius, Bureaugard, \& Cohen, 1991; Kahn et al., 1999; Leiman, Meyer, Rothschild, \& Simon, 1997). The social and environmental risk factors identified here as predictors of major depression hold potential for identifying depressed mothers in welfare offices, job training programs, and other nonclinical settings. Questions about food insufficiency, for example, require no specialized training to administer, and could readily be incorporated into intake interviews conducted in such settings.

The findings of this study also have practical implications for intervention to reduce the prevalence of depression among current and former welfare recipients. Although major advances have been made in the development of specific and effective interventions for major depression (Katon et al., 1995; Schulberg, Katon, Simon, \& Rush, 1998; Wells et al., 1996), depressed patients have a sub- 
stantial rate of relapse, even when treated (Kupfer, 1993; Lin et al., 1998). Recommendations for reducing the likelihood of relapse in recovery from major depression-an occurrence that, as noted earlier, increases the risk of chronicity and disability-include educating patients to recognize their individual early warning symptoms, specific behavioral regimens to boost medication adherence, and psychoeducational techniques to improve adaptation to acute and chronic stressors (Lin et al., 1998).

Based on the current cross-sectional data, no conclusions can be drawn as to the effects on major depression of receiving Food Stamps or participating in other programs associated with alleviating the risk factors that have been identified here. However, if confirmed by longitudinal research, these data would suggest that relapse prevention in this high-risk population might be improved by reducing maternal exposure to depressive social and environmental stressors. Assurance of adequate household food supplies, for example, might substantially reduce the odds of maternal depression; it could, thus, be cost-effective relative to maintenance pharmacotherapy, and obviate the undesirable side effects of antidepressant medications (Lin et al., 1998; Schulberg et al., 1995).

Finally, the findings reported here have implications for the development of interventions to prevent the onset of depression. To our knowledge, there have been no programs aimed at preventing depression among high-risk mothers by reducing their exposure to risk factors such as food insufficiency, neighborhood hazards, violence, or discrimination. A recent report by the National Advisory Mental Health Council Workgroup on Mental Disorders Prevention Research (1998) found that preventive intervention strategies have "primarily focused on changing individual-level processes, giving less attention to change in other, larger units such as family, school, and community, and how these larger units interact with individual-level factors and with each other to lead to the development of mental disorders" (p. 27). Pending confirmation by future research, many of the specific risk factors identified in the present study could provide the basis for environmentally focused preventive interventions-including interventions at the policy level-to reduce the incidence of major depression in high-risk mothers. It is our hope that the findings of this study will stimulate additional research in this important area.

\section{References}

Almeida, D.M., \& Kessler, R.C. (1998). Everyday stressors and gender differences in daily distress. Journal of Personality and Social Psychology, 75, 670-680.

Amaro, H., Russo, N.F., \& Johnson, J. (1987). Family and work predictors of psychological well-being among Hispanic women professionals. Psychology of Women Quarterly, 11, 505-521.

American Psychiatric Association. (1987). Diagnostic and statistical manual of mental disorders (Third ed., rev.), Washington, DC: Author.

Bassuk, E.L., Browne, A., \& Buckner, J.C. (1996). Single mothers and welfare. Scientific American, 275, 60-63.

Bindman, A.B., Grumbach, K., Osmond, D., Vranizan, K., \& Stewart, A.L. (1996). Primary care and receipt of preventive services. Journal of General Internal Medicine, II, 269-276.

Blanchard, E.B., Buckley, T.C., Hickling, E.J., \& Taylor, A.E. (1998). Posttraumatic stress disorder and comorbid major depression: Is the correlation an illusion? Journal of Anxiety Disorders, 12, 21-37.

Blazer, D.G., Kessler, R.C., McGonagle, K.A., \& Swartz, M.S. (1994). The prevalence and distribution of major depression in a national community sample: The National Comorbidity Survey. American Journal of Psychiatry. 15I, 983-989.

Bleich, A., Koslowsky, M., Dolev, A., \& Lerer, B. (1997). Posttraumatic stress disorder and depression. British Journal of Psychiatry, 170, 479-482.

Bobo, L. (1995). Surveying racial discrimination: Analyses from a multiethnic labor market (Working Paper \#75). New York: Russell Sage Foundation.

Booth, C.L., Mitchell, S.K., Barnard, K.E., \& Spieker, S.J. (1989). Development of maternal social skills in multiproblem families: Effects on the mother-child relationship. Developmental Psychology, 25, 403-412.

Boyce, P., Harris, M., Silove, D., Morgan, A., Wilhelm, K., \& Hadzi-Pavlovic, D. (1998). Psychosocial factors associated with depression: A study of socially disadvantaged women with young children. Journal of Nervous \& Mental Disease, 186. 3-11.

Breslau, N., \& Davis, G. C. (1986). Chronic stress and major depression. Archives of General Psychiatry, 43, 309-314.

Breslau, N., Davis, G.C., Peterson, E.L., \& Schultz, L.R. (1997). Psychiatric sequelae of posttraumatic stress disorder in women. Archives of General Psychiatry, 54, 81-87.

Bromet, E., Sonnega, A., \& Kessler, R.C. (1998). Risk factors for DSM-III-R posttraumatic stress disorder: Findings from the National Comorbidity Survey. American Journal of Epidemiology, 147, 352-361.

Brown, C., Schulberg, H.C., Madonia, M.J., Shear, M.K., \& Houck, P.R. (1996). Treatment outcomes for primary care patients with major depression and lifetime anxiety disorders. American Journal of Psychiatry, 153, 1293-1300.

Bruce, M.L., Takeuchi, D.T., \& Leaf, P.J. (1991). Poverty and psychiatric status. Archives of General Psychiatry, 48, $470-474$

Chavkin, W., Romero, D., \& Wise, P.H. (2000). State welfare reform policies and declines in health insurance. American Journal of Public Health, 90, 900-908.

Checkley, S. (1992). Neuroendocrine mechanisms and the precipitation of depression by life events. British Journal of Psychiatry, 15(Suppl). 7-17.

Checkley, S. (1996). The neuroendocrinology of depression and chronic stress. British Medical Bulletin, 52, 597-617.

Coic, J.D., Watt, N.F., West, S.G., Hawkins, J.D., Asarnow, J.R., Markman, H.J., Ramey, S.L., Shure, M.B., \& Long, B. (1993). The science of prevention: A conceptual framework 
and some directions for a national research program. American Psychologist, 48, 1013-1022.

Cornelius, L.J., Bureaugard, K., \& Cohen, J. (1991). Usual sources of medical care and their characteristics (National Medical Expenditure Survey Research Findings 11). Rockville, MD: Public Health Service (ACPHR Pub. No. 91-0042)

Coryell, W., Endicott, J., \& Keller, M. (1990). Outcome of patients with chronic affective disorder: A five-year followup. American Journal of Psychiatry, 147, 1627-1633.

Culbertson, F.M. (1997). Depression and gender: An international review. American Psychologist, 52, 25-31.

Danziger, S., \& Gottschalk, P. (1995). America Unequal. Cambridge, MA: Harvard University Press.

Danziger, S.K., Corcoran, M.E., Danziger, S., Heflin, C.M., Kalil, A., Levine, J.A., Rosen, D., Seefeldt, K.S., Siefert, K., \& Tolman, R. (2000). Barriers to the employment of welfare recipients. In R. Cherry \& W. Rodgers (Eds.), Prosperity for all? The economic boom and African Americans (pp. 245-278). New York: Russell Sage Foundation,

Field, T. (1992). Infants of depressed mothers. Development and Psychopathology, 4, 49-66.

Ford, D. (1994). Recognition and underrecognition of mental disorders in adult primary care. In J. Miranda, A. Hohmann, C. Attkisson, \& D. Larson (Eds.), Mental disorders in primary care (pp. 186-205). San Francisco: Jossey-Bass.

Furstenberg, F.F., Jr., Cook, T.D., Eccles, J., Elser, G.H., \& Sameroff, A. (1998). Managing to make it: Urban families in high-risk neighborhoods. Unpublished manuscript.

Garret, B., \& Holahan, J. (2000). Health insurance coverage after welfare reform. Health Affairs, 19, 175-184.

Gerber, P.D., Barrett, J., Barrett, J., Manheimer, E., Whiting, R., \& Smith, R. (1989). Recognition of depression in internists in primary care: A comparison of internist and gold standard psychiatric assessments. Journal of General Internal Medicine, 4, 7-13.

Heneghan, A.M., Silver, E.J., Bauman, L.J., Westbrook, L.E., \& Stein, R.E, (1998). Depressive symptoms in inner-city mothers of young children: Who is at risk? Pediatrics, 102 , 1394-1400.

Heuser, I. (1998). The hypothalamic-pituitary-adrenal system in depression. Pharmacopsychiatry, 31, 10-13.

Hobfoll, S.E., Ritter, C., Lavin, J., Hulsizer, M.R., \& Cameron, R.P. (1995). Depression prevalence and incidence among inner-city pregnant and postpartum women. Journal of Consulting and Clinical Psychology, 63, 445-453.

Jargowsky, P. (1997). Poverty and place: Gheltos, barrios, and the American ciry. New York: Russell Sage Foundation.

Judd, L.L., Kessler, R.C., Paulus, M.P., Zeller, P.V., Wittchen, H.U., \& Kunovac, J.L. (1998). Comorbidity as a fundamental feature of generalized anxiety disorders: Results from the National Comorbidity Study (NCS). Acta Psychiatrica Scandinavica, 98(Suppl. 393), 6-11.

Kahn, R.S., Wise, P.H., Finkelstein, J.A., Bernstein, H.H., Lowe, J.A., \& Homer, C.J. (1999). The scope of unmet maternal health needs in pediatric settings. Pediatrics, 103 , 576-581.

Kathol, R.G., Jaeckle, R.S., Lopez, J.F., \& Meller, W.H. (1989). Pathophysiology of IPA axis abnormalities in patients with major depression: An update. American Journal of Psychiatry, 146, 311-317.

Katon, W., Von Korft, M., Lin, E., Walker, E., Simon, G.E., Bush, T., Robinson, P. \& Russo, J. (1995). Collaborative management to achieve treatment guidelines: impact on depression in primary care. Journal of the American Medical Association, 273, 1026-1031.

Kendler, K.S. (1995). Genetic epidemiology in psychiatry. Archives of General Psychiatry, 52, 895-899.

Kendler, K.S. (1997). Major depression and generalised anxiety disorder. Same genes, (partly) different environments- revisited. British Journal of Psychiarry, 168(Suppl. 30), 68-75.

Kendler, K.S. (1998). Major depression and the environment: A psychiatric genetic perspective. Pharmacopsychiatry, 3I, 5-9.

Kendler, K.S., Karkowski, L.M., \& Prescott, C.A. (1998). Stressful life events and major depression: Risk period, long-term contextual threat and diagnostic specificity. Journal of Nervous \& Mental Disease, 186, 661-669.

Kendler, K.S., \& Karkowski-Shuman, L.M. (1997). Stressful life events and genetic liability to major depression: Genetic control of exposure to the environment. Psychological Medicine, 27, 539-547.

Kendler, K.S., Kessler, R.C., Neale, M.C., Heath, A.C., \& Eaves, L.J. (1993). The prediction of major depression in women: Toward an integrated etiological model. American Journal of Psychiatry, 150, 1139-1148.

Kendler, K.S., Kessler, R.C., Walters, E.E., MacLean, C., Neale, M.C., Health, A.C., \& Eaves, L.J. (1995). Stressful life events, genetic liability, and onset of an episode of major depression in women. American Journal of Psychiatry, 152, 833-842.

Kessler, R.C., Andrews, G., Morczek, D., Ustun, B., \& Wittchen, H.U. (in press). The World Health Organization Composite International Diagnostic Interview Short-Form (CIDI-SF). International Journal of Methods in Psychiatric Research.

Kessler, R.C., Davis, C.G., \& Kendler, K.S. (1997). Childhood adversity and adult psychiatric disorder in the US National Comorbidity Survey. Psychological Medicine, 27, 1101-1119.

Kessler, R.C., Nelson, C.B., McGonagle, K.A., Liu, J., Swartz, M., \& Blazer, D.G. (1996). Comorbidity of DSM-IIl-R Major Depressive Disorder in the general population: Results from the US National Comorbidity Survey. British Journal of Psychiatry, 168(Suppl. 30), 17-30.

Kessler, R.C., McGonagle, K.A., Zhao, S., Nelson, C.B., Hughes, M., Eshleman, S., Wittchen, H.U., \& Kendler, K.S. (1994). Lifetime and 12-month prevalence of DSM-III-R psychiatric disorders in the United States: Results from the National Comorbidity Survey. Archives of General Psychiatry, 51, 8-19

Kessler, R.C., Mickelson, K.D., and Williams, D.R. (1999). The prevalence, distribution, and mental health correlates of perceived discrimination in the United States, Journal of Health and Social Behavior, 40, 208-230.

Kessler, R.C., Zhao, S., Blazer, D.G., \& Swartz, M. (1997). Prevalence, correlates, and course of minor depression and major depression in the National Comorbidity Survey. Journal of Affective Disorders, 45, 19-30.

Kiraly, S.J., Ancill, R.J., \& Dimitrova, G. (1997). The relationship of endogenous cortisol to psychiatric disorder: A review. Canadian Journal of Psychiarry, 42. 415-420.

Ḱrieger, N., Rowley, D.L., Herman, A.A., Avery, B., \& Phillips, M.T. (1993). Racism, sexism, and social class: Implications for studies of health, disease, and well-being. American Journal of Preventive Medicine, 9(6 Suppl.), 82-122.

Krieger, N., \& Zierler, S. (1995). What explains the public's health? A call for epidemiologic theory. Epidemiology. 7. 107-109.

Kupfer, D.J. (1993). Management of recurrent depression. Journal of Clinical Psychiarry, 54(Suppl. 2), 29-33.

Landrine, H.. \& Klonoff, E.A. (1996). The Schedule of Racist Events: A measure of racial discrimination and a study of its negative physical and mental health consequences. Journal of Black Psychology, 22, 144-168.

Leadbeater, B.J., \& Bishop, S.J. (1994). Predictors of behavior problems in preschool children of inner-city Afro-American and Puerto Rican adolescent mothers. Child Development, 65, 638-648. 
Leiman, J.M., Meyer, J.E., Rothschild, N., \& Simon, L.J. (1997). Selected facts on US women's health: A chart book. New York: Commonwealth Fund.

Levitan, R.D., Parikh, S.V., Lesage, A.D., Hegadoren, K.M., Adams, M., Kennedy, S.H., \& Goering, P. N.(1998). Major depression in individuals with a history of childhood physical or sexual abuse: Relationship to neurovegative features, mania, and gender. American Journal of Psychiatry. 155. 1746-1752

Lin, E.H., Katon, W.J., Von Korff, M., Russo, J.E., Simon, G.E., Bush, T.M., Rutter, C.M., Walker, E.A., \& Ludman, E. (1998). Relapse of depression in primary care: Rate and clinical predictors. Archives of Family Medicine, 7, 443449.

Link, B.G., \& Phelan, J.C. (1995). Social conditions as fundamental causes of disease. Journal of Health and Social Behavior (Special lssue), 80-94.

Macintyre, S., Maclver, S., \& Sooman, A. (1993). Area, class, and health: should we be focusing on places or people? Journal of Social Policy, 22, 213-234.

McKinlay, J.B. (1993). The promotion of health through planned sociopolitical change: Challenges for research and policy. Social Science and Medicine, 36, 109-117.

Merikangas, K.R. (1990). Comorbidity for anxiety and depression: Review of family and genetic studies. In J.D. Maser \& C.R. Cloninger (Eds.), Comorbidity of mood and anxiety disorders (pp. 331-348). Washington, DC: American Psychiatric Press.

National Advisory Mental Health Council. (1996). Basic behavioral science research for mental health: Sociocultural and environmental processes. American Psychologist, 5I, 722-731.

National Advisory Mental Health Council Work Group on Mental Disorders Prevention Research. (1998). Priorities for prevention research at NIMH (NIH Pub. No. 98-4321). Rockville, MD: National Institute of Mental Health.

National Center for Health Statistics. (1994). Plan and operation of the Third National Health and Nutrition Examination Survey, 1988-1994 (Vital and Health Statistics Ser. 1, No. 32). Hyattsville, MD: Author.

National Institutes of Health/National Institute of Mental Health. (1996). A plan for prevention research for the $\mathrm{Na}$ tional Institute of Mental Health: A report to the National Advisory Mental Health Council (NIH Publication No. 964093). Rockville, MD: Author.

Noh, S., Beiser, M., Kaspar, V., Hou, F., \& Rummens, J. (1999). Perceived racial discrimination, depression, and coping: A study of Southeast Asian refugees in Canada. Journal of Health and Social Behavior, 40, 193-207.

Nolen-Hoeksema, S. (1990). Sex differences in depression Stanford, CA: Stanford University Press.

Olfson, M., Fireman, B., Weissman, M.M., Leon, A.C., Sheehan, D.V., Kathol, R.G., Hoven, C., \& Farber, L. (1997). Mental disorders and disability among patients in a primary care group practice. American Journal of Psychiatry, 154 1734-1740.

Padgett, D.K. (1997). Women's mental health: Some directions for research. American Journal of Orthopsychiatry, 67. 522-534.

Pearlin, L., Menaghan, E.M., Lieberman, M.A., \& Mulan, J.T. (1981). The stress process. Journal of Health and Social Behavior. 22, 337-356.

Perez-Stable, E.J., Miranda, J., Munoz, R.F., \& Ying, Y.W. (1990). Depression in medical outpatients: Underrecognition and misdiagnosis. Archives of Internal Medicine, 150 . 1083-1088.

Post, R. M. (1992). Transduction of psychosocial stress into the neurobiology of recurrent affective disorder. American Journal of Psychiatry, 149, 999-1010.
Quint, J.C., Bos, J.M, \& Polit, D.F. (1997). New Chance: Final report on a comprehensive program for young mothers in poverty and their children. New York: Manpower Demonstration Research Corp.

Reiss, D., \& Price, R.H. ( 1996). National research agenda for prevention research: The National Institute of Mental Health Report. American Psychologist, 5l, 1109-11 I5.

Ren, X.S., Amick, B.C., \& Williams, D.R. (1999). Racial/ethnic disparities in health; The interplay between discrimination and socioeconomic status. Ethnicity and Disease, 9, $151-65$.

Robins, L.N., \& Regier, D. (1991). Psychiatric disorders in America: The Epidemiologic Catchment Area Study. New York: Free Press.

Robins, L.N., Wing, J., Wittchen, H.U., Helzer, J.E., Babor, T.F., Burke, J.D., Farmer, A., Jablenski, A., Pickens, R., Regier, D.A., Sartorius, N., \& Towle, L.M. (1988). The Composite International Diagnostic Interview: An epidemiologic instrument suitable for use in conjunction with different diagnostic systems and in different cultures. Archives of General Psychiatry, 45, 1069-1077.

Roy, A. (1987). Five risk factors for depression. British Journal of Psychiatry, 150, 536-541.

Rubin, R.T. (1989). Pharmacoendocrinology of major depression. Psychiatric Neural Sciences, 238, 259-267.

Rumbaut, R.G. (1994). The crucible within: Ethnic identity, self-esteem, and segmented assimilation among children of immigrants. International Migration Review, 28, 748-794.

Salomon, A., Bassuk, S.S., \& Brooks, M.G. (1996). Patterns of welfare use among poor and homeless women. American Journal of Orthopsychiatry, 66, 510-525.

Sameroff, A.J., Seifer, R., Baldwin, A., \& Baldwin, C. (1993). Stability of intelligence from preschool to adolescence: The influence of social and family risk factors. Child Development, 64, 80-97.

Sameroff, A.J., Seifer, R., \& Bartko, W.T. (1997). Environmental perspectives on adaptation during childhood and adolescence. In S.S. Luthar, J.A. Burack, D. Cicchetti, \& J.R. Weisz (Eds.), Developmental psychopathology: Perspectives on adjustment, risk and disorder (pp. 507-526). Cambridge: Cambridge University Press.

Schulberg, H.C., Katon, W.J., Simon, G.E., \& Rush, A.J. (1998). Treating major depression in primary care practice: An update of the Agency for Health Care Policy and Research Practice Guidelines. Archives of General Psychiatry, $55,1121-1127$.

Schulberg, H.C., Madonia, M.J., Block, M.R., Coulehan, J.L., Scott, C.P., Rodriguez, E., \& Black, A. (1995). Major depression in primary care practice: Clinical characteristics and treatment implications. Psychosomatics, 36, 129-137.

Seeman, M.V. (1997). Psychopathology in women and men: Focus on female hormones. American Journal of Psychiatry. 154, 1641-1647.

Shalev, A.Y., Freedman, S., Peri, T., Brandes, D., Sahar, T., Orr, S.P., \& Pitman, R.K. (1998). Prospective study of posttraumatic stress disorder and depression following trauma. American Journal of Psychiatry, 155, 630-637

Sherbourne, C.D., \& Wells, K.B. (1997). Course of depression in patients with comorbid anxiety disorders. Journal of $A f-$ fective Disorders, 43, 245-250.

Silver, E.J., Westbrook, L.E., \& Stein, R.E. (1998). Relationship of parental psychological distress to consequences of chronic health conditions in children. Journal of Pediatric Psychology, 23, 5-15.

Solomon, Z., Bleich, A., Koslowsky, M, Kron, S., Lerer, B., \& Waysman, M. (1991). Posttraumatic stress disorder: Issues of comorbidity. Journal of Psychiatric Research, 25 , 89-94.

Stokes, P.E. (1995). The potential role of excessive cortisol 
induced by HPA hyperfunction in the pathogenesis of depression. European Neuropsychopharmacology, 5(Suppl.), 77-82.

Straus, M.A., \& Gelles, R.J. (1986). Societal change and change in family violence from 1975 to 1985 as revealed by two national surveys. Journal of Marriage and the Family, $48,465-479$.

Thompson, V.L.S. (1996). Perceived experiences of racism as stressful life events. Community Mental Health Journal, 32, 223-33.

Ustun, T.B., \& Von Korff, M.(1995). Primary mental health services: Access and provision of care. In T.B. Ustun \& N. Sartorius (Eds.), Mental illness in general health care: An international study. New York: John Wiley.

U.S. Bureau of the Census (1998). Poverty in the United States: 1997 (Current Population Reports, Series P-60, No. 201). Washington, DC: U.S. Govemment Printing Office.

Vander Stoep, A., \& Link, B.G. (1998). Social class, ethnicity, and mental illness: The importance of being more than earnest. American Journal of Public Health, 88, 1396-1402.

Von Korff, M., Ormel, J., Katon, W.J., \& Lin, E.H. (1992). Disability and depression among high utilizers of health care: A longitudinal analysis. Archives of General Psychiatry, 49, 152-156.

Von Korff, M., Shapiro, S., Burke, J.D., Teitlebaum, M., Skinner, E.A., German, P., Turner, R.W., Klein, L., \& Burns, B. (1987). Anxiety and depression in a primary care clinic. Archives of General Psychiatry, 49, 91-100.

Ware, J., \& Sherbourne, C.D. (1992). The MOS 36-item ShortForm Health Survey (SF-36): Conceptual framework and item selection. Medical Care, 30, 473-483.

Weissman, M.M., \& Olfson, M. (1995). Depression in women: Implications for health care research. Science, 269, 799-801.

Weissman, M.M., Warner, V., Wickramaratne, P.J., Moreau, D., \& Olfson, M. (1997). Offspring of depressed parents: 10 years later. Archives of General Psychiatry, 54, 932-940.

Wells, K.B., Burnam, M.A., Rogers, W., Hays, R., \& Camp, P. (1992). The course of depression in adult outpatients: Re- sults from the Medical Outcomes Study. Archives of General Psychiatry, 49, 788-794.

Wells, K.B., Sturm, R., Sherbourne, C.D., \& Meredith, L.S. (1996). Caring for depression: A RAND study. Cambridge, MA: Harvard University Press.

Williams, D.R. (1997). Race and health: Basic questions, emerging directions. Annals of Epidemiology, 7, 322-333.

Williams, D.R. (1999). Race, SES, and health: The added effects of racism and discrimination. Annals of the New York Academy of Sciences, 896, 173-178.

Williams, D.R., \& Chung, A-M. (In press). Racism and health. In R.C. Gibson \& J.S. Jackson (Eds.), Health in Black America. Thousand Oaks, CA: Sage Publications.

Williams, D.R., Takeuchi, D.T., \& Adair, R.K. (1992). Socioeconomic status and psychiatric disorder among Blacks and Whites. Social Forces, 7l, 179-194.

Williams, D.R., Yu, Y., Jackson, J.Sı, \& Anderson, N.B. (1997). Racial differences in physical and menttal health: Socioeconomic status, stress, and discrimination. Journal of Health Pyschology, 2, 335-351.

Wittchen, H.U. (1994). Reliability and validity studies of the WHO-Composite International Diagnostic Review (CIDI): A critical review. Journal of Psychiatric Research. 28, 57-84.

Wittchen, H.U., Essau, C.A., von Zewrssen, D., Krieg, J.C., \& Zaudig, M. (1992). Lifetime and six-month prevalence of mental disorders in the Munich follow-up study. European Archives of Psychiatry and Clinical Neuroscience, 24l, 247-258.

World Health Organization. (1990). Composite International Diagnostic Review (CIDI, Version 1.0). Geneva, Switzerland: Author.

Yehuda, R. (1998). Psychoneuroendocrinology of posttraumatic stress disorder. Psychiatric Clinics of North America. $21,359-379$.

Young, E.A., Abelson, J.L., Curtis, G.C., \& Nesse, R.M. (1997). Childhood adversity and vulnerability to mood and anxiety disorders. Depression \& Anxiety, 5, 66-72. 